\title{
Biodegradation of ochratoxin A by Pediococcus parvulus isolated from Douro wines
}

\author{
Luís Abrunhosa ${ }^{\mathrm{a}, *}$, António Inês ${ }^{\mathrm{b}}$, Ana I. Rodrigues ${ }^{\mathrm{a}}$, Ana Guimarães ${ }^{\mathrm{a}}$, Vânia L. Pereira ${ }^{\mathrm{b}}$, Pier Parpot ${ }^{\mathrm{c}}$, \\ Arlete Mendes-Faia ${ }^{b}$, Armando Venâncio ${ }^{a}$ \\ a CEB-Centre of Biological Engineering, University of Minho, Campus de Gualtar, 4710-057 Braga, Portugal

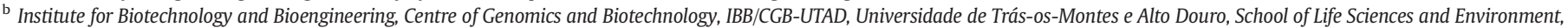 \\ Edificio de Enologia, Apartado 1013, 5001-801 Vila Real, Portugal \\ ${ }^{c}$ Centre of Chemistry, University of Minho, Campus de Gualtar, 4710-057 Braga, Portugal
}

\section{A R T I C L E I N F O}

\section{Article history:}

Received 25 March 2014

Received in revised form 15 July 2014

Accepted 16 July 2014

Available online 23 July 2014

\section{Keywords:}

Pediococcus parvulus

Ochratoxin A

Biodegradation

Detoxification

\begin{abstract}
A B S T R A C T
Lactic acid bacteria ( $\mathrm{LAB}$ ) are a promising solution to reduce exposure to dietary mycotoxins because of the unique mycotoxin decontaminating characteristic of some LAB. Ochratoxin A (OTA) is one of the most prominent mycotoxins found in agricultural commodities. The present work reports on the ability of Pediococcus parvulus strains that were isolated from Douro wines that spontaneously underwent malolactic fermentation to detoxify OTA. These strains were identified and characterised using a polyphasic approach that employed both phenotypic and genotypic methods. When cultivated on OTA-supplemented MRS media, OTA was biodegraded into OT $\alpha$ by certain P. parvulus strains. The presence of OT $\alpha$ was confirmed using LC-MS/MS. The conversion of OTA into OT $\alpha$ indicates that the OTA amide bond was hydrolysed by a putative peptidase. The rate of OTA biodegradation was found to be dependent on the inoculum size and on the incubation temperature. Adsorption assays with dead $P$. parvulus cells showed that approximately $1.3 \% \pm 1.0$ of the OTA was adsorbed onto cells wall, which excludes this mechanism in the elimination of OTA by strains that degrades OTA. Under optimum conditions, 50\% and $90 \%$ of OTA were degraded in 6 and $19 \mathrm{~h}$, respectively. Other LAB strains that belonged to different species were tested but did not degrade OTA. OTA biodegradation by P. parvulus UTAD 473 was observed in grape must. Because some $P$. parvulus strains have relevant probiotic properties, the strains that were identified could be particularly relevant to food and feed applications to counteract the toxic effects of OTA.
\end{abstract}

(C) 2014 Elsevier B.V. All rights reserved.

\section{Introduction}

Lactic acid bacteria (LAB) are generally thought to be beneficial microorganisms and are widely studied because of their probiotic properties (Naidu et al., 1999). They are commonly used for the production of fermented food products, such as yogurt, cheese, fermented milks, meat, fish, vegetables (sauerkraut and pickles), certain beer brands and wines (Stiles, 1996). For the production of wine, LAB are involved in malolactic fermentation (MLF). MLF is a secondary fermentation process that is used to improve the quality of some wines. MLF reduces acidity (via the conversion of $\mathrm{L}-$ malic acid to $\mathrm{L}$ - lactic acid), increases microbial stability and improves the aroma, flavour and mouthfeel (du Toit et al., 2010; Kunkee, 1967).

While not widely known, some LAB are able to control potential health hazards that are linked to mycotoxins (Abrunhosa et al., 2010;

\footnotetext{
* Corresponding author at: Departamento de Engenharia Biológica, Universidade do Minho, Campus de Gualtar, 4710-057 Braga, Portugal. Tel.: + 351 253601986; fax: +351253604429 .

E-mail address: luisjap@deb.uminho.pt (L. Abrunhosa).
}

Dalié et al., 2010; Salminen et al., 2010; Shetty and Jespersen, 2006). Mycotoxins are acutely toxic fungal secondary metabolites that can be found in agricultural commodities. Many mycotoxins are carcinogenic, mutagenic, teratogenic, neurotoxic and immunosuppressive (Bennett and Klich, 2003). Therefore, the levels of mycotoxins in food and feed products should be reduced to the lowest technologically possible levels. Accordingly, several physical, chemical and biological methods are currently available to control the levels of mycotoxins (EFSA, 2009). Nevertheless, the demand for innovative solutions continues to overcome the limitations of the current strategies for reducing mycotoxin levels. In particular, new microorganisms that are actively able to detoxify mycotoxins are needed.

In this context, LAB are of particular interest to researchers, and several strains that bind aflatoxins (El-Nezami et al., 1998), trichothecenes (H.S. El-Nezami et al., 2002), zearalenone (H. El-Nezami et al., 2002), ochratoxin A and patulin (Fuchs et al., 2008) have been identified in model systems. Some strains were also successfully tested in vivo. The LC-705 Lactobacillus rhamnosus strain was shown to reduce the intestinal adsorption of aflatoxin $\mathrm{B}_{1}$ by $74 \%$ in chickens (El-Nezami et al., 2000). Some commercial products that are based on this and 
other LAB strains are already available (EFSA, 2009; Salminen et al., 2010). In most reports, the binding of mycotoxins by LAB was determined to be the main mechanism for detoxification (Dalié et al., 2010; El-Nezami et al., 2004). Exopolysaccharides and peptidoglycans are considered to be the most plausible binding molecules (Dalié et al., 2010). However, the involvement of metabolic conversion was suggested in some studies but the full mechanistic pathways was not fully elucidated (Fuchs et al., 2008; Niderkorn et al., 2007).

Ochratoxin A (OTA) is an important mycotoxin that is found in agricultural commodities. It is produced by some Penicillium and Aspergillus species and is mainly found in cereals, coffee beans, cocoa beans, grapes, raisins, wine, figs, pork meat and spices (Jørgensen, 2005). OTA is nephrotoxic, hepatotoxic, immunotoxic, teratogenic and carcinogenic (category 2B) (Bennett and Klich, 2003). Chemically, it is composed of an isocoumarin moiety (known as ochratoxin $\alpha$ ) and a L- $\beta$-phenylalanine molecule that are linked by an amide bond (van der Merwe et al., 1965). Ochratoxin $\alpha$ (OT $\alpha$ ) is considered to be non-toxic and has an elimination half-life that is 10-times less than that of OTA (Li et al., 1997). In animals and humans, the conversion of OTA into OT $\alpha$ via hydrolysis of the amide bond constitutes the predominant detoxification pathway of OTA (Wu et al., 2011). Several proteolytic enzymes (Abrunhosa et al., 2006, 2010), microorganisms (Abrunhosa et al., 2010; Varga et al., 2010) and plant cells (Ruhland et al., 1996) have been shown to hydrolyse this amide bound to detoxify OTA. In the present work, we investigate the capacity of LAB isolated from Douro wines to biodegrade OTA through this detoxification pathway.

\section{Materials and methods}

\subsection{Identification and characterisation of $L A B$}

The LAB strains that were used in the present study were obtained from the UTAD-LAB collection. This collection had been previously isolated from red wines of the Douro region that had spontaneously undergone MLF. Several species of Lactobacillus, Oenococcus oeni, Pediococcus parvulus and Leuconostoc mesenteroides were identified (Inês, 2007). The isolates were also screened for enzymes considered to be valuable for obtaining a high quality wine, as for example, the presence of $\beta$-glucosidase and malolactic enzymes, and absence of histidine, tyrosine decarboxylases and enzymes from the arginine deaminase pathway. The strains were verified phenotypically on adequate culture media and were verified genotypically by identifying the genes that encoded the enzymes of interest (Inês et al., 2008). The following 19 strains used in the present study were randomly picked from different genera: 9 strains of 0 . oeni, 6 strains of $P$. parvulus and 4 strains of Lactobacillus plantarum (listed in Table 1). The reidentification of the strains that had the ability to biodegrade OTA was performed using the simplified key for phenotypic differentiation of species within the genera Pediococcus and Tetragenococcus as proposed by Holzapfel et al. (2006) and validated by a BLAST analysis of partial sequences of the $16 \mathrm{~S}$ rRNA gene (497-836 nt). A phylogenetic tree based on the partial sequences was constructed by applying Kimura 2-parameter (Kimura, 1980) and Neighbor-Joining methods (Saitou and Nei, 1987) as grouping method. The tree was rooted by using Bifidobacterium bifidum sequence as outgroup. Bootstrap values were calculated from 1000 replications (Felsenstein, 1985). Evolutionary analyses were conducted in MEGA5 (Tamura et al., 2011). The reference strains O. oeni CECT $217^{\mathrm{T}}$, P. parvulus CECT $7350^{\mathrm{T}}$ and L. plantarum CECT $748^{\mathrm{T}}$ were used as controls and were purchased from the Spanish Type Culture Collection (CECT, University of Valencia, Spain).

\subsection{Screening for OTA biodegradation}

Strains were cultured from frozen aliquots onto Petri dishes with MRS agar. The plates were then incubated at $30{ }^{\circ} \mathrm{C}$ in $2.5 \mathrm{~L}$ anaerobic jars that were prepared with AnaeroGen ${ }^{\mathrm{TM}}$ sachet (AN0025, Oxoid) and the anaerobic indicator (BR0055, Oxoid). Unless stated otherwise, strains were always cultivated under anaerobic conditions. Subsequently, strains were cultured in sterile microcentrifuge tubes with $1 \mathrm{~mL}$ of MRS broth (Oxoid) at $30{ }^{\circ} \mathrm{C}$ for 2 days. The inoculum for each strain was propagated at $30{ }^{\circ} \mathrm{C}$ for 7 days in falcon tubes that contained $5 \mathrm{~mL}$ of MRS broth. The inoculum concentration was determined by counting CFU in MRS agar plates by serially diluting the inoculums. The concentration was adjusted as needed using sterile MRS broth. To study the ability of LAB strains to degrade OTA, a MRS broth medium that was

Table 1

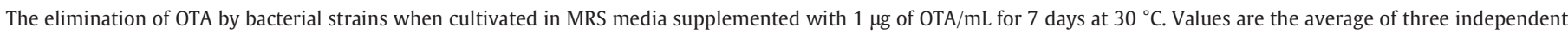
replicates \pm standard deviation.

\begin{tabular}{|c|c|c|c|c|}
\hline LAB species & Strain & OTA $(\mu / \mathrm{mL})$ & $\mathrm{OT} \alpha(\mu / \mathrm{mL})$ & OTA eliminated (\%) \\
\hline Controls & - & $1.173 \pm 0.033$ & 0 & 0 \\
\hline Lactobacillus plantarum & CECT $748^{\mathrm{T}}$ & $1.013 \pm 0.004$ & 0 & $14 \pm 0.4$ \\
\hline Oenococcus oeni & CECT $217^{\mathrm{T}}$ & $0.936 \pm 0.034$ & 0 & $20 \pm 2.9$ \\
\hline Pediococcus parvulus & CECT $7350^{\mathrm{T}}$ & $0.986 \pm 0.028$ & 0 & $16 \pm 2.4$ \\
\hline \multirow[t]{4}{*}{ Lactobacillus plantarum } & UTAD 346 & $1.051 \pm 0.007$ & 0 & $10 \pm 0.6$ \\
\hline & UTAD 350 & $1.023 \pm 0.006$ & 0 & $13 \pm 0.5$ \\
\hline & UTAD 460 & $1.059 \pm 0.004$ & 0 & $10 \pm 0.4$ \\
\hline & UTAD 461 & $1.041 \pm 0.007$ & 0 & $11 \pm 0.6$ \\
\hline \multirow[t]{9}{*}{ Oenococcus oeni } & UTAD 224 & $0.988 \pm 0.004$ & 0 & $16 \pm 0.3$ \\
\hline & UTAD 228 & $0.997 \pm 0.003$ & 0 & $15 \pm 0.3$ \\
\hline & UTAD 244 & $0.997 \pm 0.006$ & 0 & $15 \pm 0.5$ \\
\hline & UTAD 279 & $1.008 \pm 0.009$ & 0 & $14 \pm 0.7$ \\
\hline & UTAD 295 & $0.990 \pm 0.009$ & 0 & $16 \pm 0.8$ \\
\hline & UTAD 296 & $0.999 \pm 0.005$ & 0 & $15 \pm 0.4$ \\
\hline & UTAD 474 & $0.993 \pm 0.005$ & 0 & $15 \pm 0.4$ \\
\hline & UTAD 602 & $1.009 \pm 0.006$ & 0 & $14 \pm 0.5$ \\
\hline & UTAD 653 & $1.008 \pm 0.010$ & 0 & $14 \pm 0.9$ \\
\hline \multirow[t]{6}{*}{ Pediococcus parvulus } & UTAD 111B & $0.328 \pm 0.139$ & $0.635 \pm 0.117$ & $72 \pm 11.8$ \\
\hline & UTAD $168^{*}$ & $0.133 \pm 0.072$ & $0.810 \pm 0.051$ & $89 \pm 6.2$ \\
\hline & UTAD 333 & $0.037 \pm 0.007$ & $0.949 \pm 0.001$ & $97 \pm 0.6$ \\
\hline & UTAD $334^{*}$ & $0.070 \pm 0.059$ & $0.863 \pm 0.035$ & $94 \pm 5.1$ \\
\hline & UTAD 335 & $0.025 \pm 0.001$ & $0.957 \pm 0.007$ & $98 \pm 0.1$ \\
\hline & UTAD $473^{*}$ & 0 & $0.922 \pm 0.034$ & $100 \pm 0$ \\
\hline
\end{tabular}

\footnotetext{
* P. parvulus UTAD 168, P. parvulus UTAD 334 and P. parvulus UTAD 473 are now deposited in the Spanish Type Culture Collection (CECT, University of Valencia, Spain) with the following
} codes, respectively: Pediococcus parvulus CECT 7950, CECT 7951 and CECT 7952. 
supplemented with $1.0 \mu \mathrm{g}$ OTA/mL (MRS-OTA) was prepared as follows. A stock solution at a concentration of $25 \mu \mathrm{g}$ of OTA $/ \mathrm{mL}$ was prepared in toluene/acetic acid (99:1, v/v) using commercial standard OTA (01877, Sigma) and stored at $-20{ }^{\circ} \mathrm{C}$ until use. The appropriate volume of the OTA stock solution was added to an Erlenmeyer flask and was evaporated to dryness at $50{ }^{\circ} \mathrm{C}$ using a gentle stream of nitrogen. The appropriated volume of MRS broth (Oxoid) was then added to the flasks. The flasks were then placed in an ultrasonic bath for 15 min to assist the solubilisation of the OTA. The media was autoclaved at $121{ }^{\circ} \mathrm{C}$ for $15 \mathrm{~min}$ and cooled. Subsequently, $5 \mathrm{~mL}$ aliquots were transferred into sterile $15 \mathrm{~mL}$ conical tubes using aseptic technique. For each strain, $5 \mathrm{~mL}$ of MRS-OTA was inoculated in triplicate with $0.1 \mathrm{~mL}$ of the prepared inoculum at a concentration of $10^{9} \mathrm{CFU} / \mathrm{mL}$. Three negative controls were also prepared using $0.1 \mathrm{~mL}$ of sterile MRS in the place of the inoculum. Tubes were incubated at $30{ }^{\circ} \mathrm{C}$ for 7 days in $2.5 \mathrm{~L}$ anaerobic jars as previously described. The culture media and bacterial cells were extracted by the addition of $5 \mathrm{~mL}$ of acetonitrile/acetic acid (99:1, v/v) to the culture tubes, which were then vortexed for $1 \mathrm{~min}$. A $2 \mathrm{~mL}$ sample was then collected and filtered into a clean $2 \mathrm{~mL}$ amber borosilicate glass vial using syringe-fitted PP filters with $0.45 \mu \mathrm{m}$ pores (Merck). This sample was preserved at $4{ }^{\circ} \mathrm{C}$ until HPLC analysis.

\subsection{Characterisation of the OTA biodegradation}

The effects of 3 factors in the biodegradation of OTA by $P$. parvulus UTAD 473 were studied. The factors evaluated were the inoculum size, OTA concentration in MRS medium and the incubation temperature. Experiments were conducted in triplicate following the procedure that has been described previously. To evaluate the effect of inoculum size, tubes with $5 \mathrm{~mL}$ of MRS-OTA were inoculated to achieve a cell concentration of $10^{3}, 10^{6}$ and $10^{9} \mathrm{CFU} / \mathrm{mL}$ and incubated at $30^{\circ} \mathrm{C}$. To evaluate the effect of OTA concentration, tubes with $5 \mathrm{~mL}$ of MRS supplemented with $0.01,0.1$ and $1.0 \mu \mathrm{g}$ OTA $/ \mathrm{mL}$ were inoculated to achieve $10^{9} \mathrm{CFU} / \mathrm{mL}$ and incubated at $30^{\circ} \mathrm{C}$. To evaluate the effect of temperature, tubes with $5 \mathrm{~mL}$ of MRS supplemented with $1.0 \mu \mathrm{g}$ OTA/mL were inoculated to achieve $10^{9} \mathrm{CFU} / \mathrm{mL}$ and incubated at 20,30 and $37{ }^{\circ} \mathrm{C}$. OTA and OT $\alpha$ levels were analysed over time by extracting and analysing three replicates on a daily basis until a maximum of 7 days of incubation, as previously described. Samples were preserved at $4{ }^{\circ} \mathrm{C}$ until HPLC analysis was performed. Three negative controls using $0.1 \mathrm{~mL}$ of sterile MRS instead of inoculum were prepared for each of the evaluated factors. The negative controls were extracted after 7 days of incubation. All the experiments were conducted in $2.5 \mathrm{~L}$ anaerobic jars.

\subsection{Evaluation of OTA adsorption to cell walls}

To investigate if OTA was adsorbing to cells walls of $P$. parvulus, dead cells from $P$. parvulus UTAD 473 were used. The inoculum was prepared as described previously. The tubes were then autoclaved at $121{ }^{\circ} \mathrm{C}$ for $15 \mathrm{~min}$. Dead cells were added to $5 \mathrm{~mL}$ of MRS-OTA in triplicate to a final concentration of $10^{9} \mathrm{CFU} / \mathrm{mL}$, and the tubes were vortex-mixed for $30 \mathrm{~s}$. The mixtures was vortexed every $15 \mathrm{~min}$ for $1 \mathrm{~h}$. Finally, tubes were centrifuged ( $9000 \times g$ for $20 \mathrm{~min}$ ), and the supernatant was collected and filtered into clean tubes using syringe-fitted PP filters with $0.2 \mu \mathrm{m}$ pores (Merck). The extraction of the ochratoxins from the supernatants was performed as previously described. The cell pellets were extracted by adding $2 \mathrm{~mL}$ of acetonitrile/water/acetic acid $(99: 99: 2, \mathrm{v} / \mathrm{v} / \mathrm{v})$ to them. After vortexing for $1 \mathrm{~min}$, the extracts were filtered into clean glass vials and preserved at $4{ }^{\circ} \mathrm{C}$ until HPLC analysis was performed.

\subsection{Analytical techniques}

Samples were analysed by HPLC with fluorescence detection, as described elsewhere with some modification (Abrunhosa and
Venâncio, 2007). Briefly, the HPLC system was comprised of a Varian Prostar 210 pump, a Varian Prostar 410 autosampler, a Jasco FP-920 fluorescence detector $\left(\lambda_{\text {exc }}=333 \mathrm{~nm}\right.$ and $\lambda_{\text {em }}=460 \mathrm{~nm}$; gain $=$ 100 ) and a Jones Chromatography 7971 column heater that was maintained at $30{ }^{\circ} \mathrm{C}$. The instrument and the chromatographic data were managed by a Varian 850-MIB data system interface and a Galaxie chromatography data system, respectively. The chromatographic separation was performed on a $\mathrm{C}_{18}$ reversed-phase YMC-Pack ODS-AQ analytical column $(250 \times 4.6 \mathrm{~mm}$ I.D., $5 \mu \mathrm{m})$ that was fitted with a pre-column with the same stationary phase. The compounds were eluted using a flow rate of $0.8 \mathrm{~mL} / \mathrm{min}$ for a $21 \mathrm{~min}$ isocratic run. The injection volume was $50 \mu \mathrm{L}$. The mobile phase was a mixture of acetonitrile/water/acetic acid (99:99:2, v/v/v) that was filtered and degassed with a $0.2 \mu \mathrm{m}$ membrane filter (GHP, Gelman). OTA was identified by comparing the retention time of the peak samples with the standards. Recorded retention times for OT $\alpha$ and OTA were approximately 7.5 and $19.8 \mathrm{~min}$, respectively. Standards with $0.5,1.0,2.5,5.0$ and $7.5 \mu \mathrm{g} /$ $\mathrm{mL}$ were prepared by serially diluting the primary OTA stock solution $(25 \mu \mathrm{g} / \mathrm{mL})$. The standards were used to elaborate the calibration curve, which was regularly checked. OTA quantification was performed by measuring the peak area and comparing it to the respective OTA calibration curve. OT $\alpha$ was quantified in equivalents of OTA.

\subsection{Ochratoxin $\alpha$ confirmation}

The $P$. parvulus UTAD 473 samples described in Table 1 were used to confirm the presence of OT $\alpha$ using LC-MS/MS. Analyses were performed using a Thermo Finnigan LXQ linear ion trap mass spectrometer that was coupled to a Finnigan surveyor HPLC system. Separation was performed on a Hydro-RP 100A phenomex column $(100 \times 3.0 \mathrm{~mm}$ I.D., $2.5 \mu \mathrm{m})$ using a mixture of acetonitrile/water/ acetic acid $(40: 60: 1, \mathrm{v} / \mathrm{v} / \mathrm{v})$ at a flow rate of $0.20 \mathrm{~mL} / \mathrm{min}$ for $40 \mathrm{~min}$. A $20 \mu \mathrm{L}$ sample was injected. Negative electrospray ionisation (ESI) was used for ion preparation. The conditions had been determined previously with a tune process to optimise the efficiency of the analysis. The operating conditions were as follows: sheath gas flow, $10 \mathrm{lb} / \mathrm{in}^{2}$; sweep gas flow, $30 \mathrm{lb} / \mathrm{in}^{2}{ }^{2}$; auxiliary gas flow, $30 \mathrm{lb} /$ in. $^{2}$; source voltage $5 \mathrm{kV}$; capillary voltage, $-45.00 \mathrm{~V}$; tube lens, $-95.87 \mathrm{~V}$.

MS/MS analysis was performed using two segments for precursor ions of 255.5 and 402.0. To identify the compounds the following parent-to-fragments were monitored: $m / z 402.0 \rightarrow 358.0$ for OTA and $m / z 255.0 \rightarrow 211.0$ for OT $\alpha$. The collision energy for the products ions $\mathrm{m} / \mathrm{z} 358.0$ and 211.0 was $35 \mathrm{eV}$. The conditions of the MS/MS analyses were as follows: $\mathrm{Q}, 0.25$; act. time, $30 \mathrm{~ms}$; act. type, CID.

\subsection{Data analysis}

The OTA concentration over time data were fitted using a logistic model adapted from recommendations of the FOCUS work group report on pesticide degradation kinetics (FOCUS, 2006). Data were fitted to the model using a nonlinear least squares fit regression using GraphPad Prism vers. 5.03 for Windows, GraphPad Software, San Diego California USA, www.graphpad.com and Eq. (1).

$$
\mathrm{S}=\mathrm{S}_{0} *\left[\frac{\mathrm{a}_{\max }}{\mathrm{a}_{\max }-\mathrm{a}_{0}+\mathrm{a}_{0} * \mathrm{e}^{(r * t)}}\right]^{\frac{\mathrm{a} \max }{r}}
$$

$S$ is the percentage of OTA present at time $t, S_{0}$ is the initial percentage of OTA present in the assay, $a_{\max }$ is the maximum value of the degradation constant, $a_{0}$ is the initial value of the degradation constant, $r$ is the microbial growth rate and $\mathrm{t}$ is the time (FOCUS, 2006). 
To perform the regression analysis, OTA data were converted to a $0-100 \%$ scale. $S_{0}$ was constrained to $100 \%$ and the initial values of $\mathrm{a}_{\max }, \mathrm{a}_{0}$ and $\mathrm{r}$ were set to $0.02,0.01$ and 0.03 , respectively. The $\mathrm{a}_{\max }, \mathrm{a}_{0}$ and $\mathrm{r}$ parameters were estimated using a fitted equation to calculate the DT50 and DT90 (the time required for $50 \%$ and $90 \%$ of the OTA to be degraded) according to Eqs. (2) and (3), respectively.

$\mathrm{DT} 50=\frac{1}{\mathrm{r}} * \ln \left[1-\frac{\mathrm{a}_{\mathrm{max}}}{\mathrm{a}_{0}} *\left(1-2^{\frac{\mathrm{r}}{\max }}\right)\right]$

DT90 $=\frac{1}{\mathrm{r}} * \ln \left[1-\frac{\mathrm{a}_{\max }}{\mathrm{a}_{0}} *\left(1-10^{\frac{\mathrm{r}}{\max }}\right)\right]$

\subsection{Evaluation of OTA biodegradation by P. parvulus in food matrices}

Inoculum of $P$. parvulus UTAD 473 was prepared by cultivating the strain in $30 \mathrm{~mL}$ MRS (Oxoid) at $30{ }^{\circ} \mathrm{C}$ for 5 days. Then the biomass was transferred to $200 \mathrm{~mL}$ of adaptation media (MRS, $50 \mathrm{~g} / \mathrm{L}$; glucose, $20 \mathrm{~g} / \mathrm{L}$; fructose, $40 \mathrm{~g} / \mathrm{L}$; malic acid, $4 \mathrm{~g} / \mathrm{L}$; Tween $80,1 \mathrm{~g} / \mathrm{L}$; ethanol, 6\%; $\mathrm{pH}$ 4.6) (Lerm, 2010) and incubated at $25^{\circ} \mathrm{C}$ for 5 days. CFU were determined by plating serial decimal dilutions in MRS and inoculum concentration adjusted to $10^{11} \mathrm{CFU} / \mathrm{mL}$. To evaluate if $P$. parvulus UTAD 473 was able to biodegrade OTA in food matrices, synthetic wine and grape must supplemented with $7 \mu \mathrm{g}$ OTA/L were used. Synthetic wine was prepared according to Mateo et al. (2010) with an ethanol content of $12.5 \%$. Grape must was prepared with grapes from the Red Globe variety as follows: grapes were blended, the juice was filtered using filter paper (G595 ${ }^{1 / 2}$, Merck), supplemented with $2 \mathrm{~g} / \mathrm{L}$ of yeast extract (Difco) and sterilized at $115^{\circ} \mathrm{C}$ during $25 \mathrm{~min}$. Experiments were conducted in Erlenmeyer flasks with $100 \mathrm{~mL}$ of synthetic wine or grape juice in triplicate. Flasks were inoculated with $1 \mathrm{~mL}$ of inoculum to reach $10^{9} \mathrm{CFU} / \mathrm{mL}$ and incubated at $25{ }^{\circ} \mathrm{C}$ for 30 days. Samples were collected over time to determine OTA (as previously described), $\mathrm{pH}$ and biomass by measuring optical density (OD) at $600 \mathrm{~nm}$.

\section{Results}

\section{1. $L A B$ identification and characterisation}

The $P$. parvulus strain identification was reconfirmed and all the strains of interest had the ability to ferment galactose, grew at $\mathrm{pH} 7.0$, grew at $35{ }^{\circ} \mathrm{C}$ and did not ferment lactose. The identification was also validated by a BLAST analysis of partial sequences of the $16 \mathrm{~S}$ rRNA gene that were obtained for the three strains, which presented an elevated capacity for OTA detoxification (Fig. 1). The three strains (P. parvulus UTAD 168, $P$. parvulus UTAD 334 and $P$. parvulus UTAD 473) are deposited in CECT with the following code numbers: $P$. parvulus CECT 7950, CECT 7951 and CECT 7952, respectively. Their 16S ribosomal RNA gene nucleotide sequences are deposited in the National Center for Biotechnology Information (NCBI) under the accession numbers KF886568, KF886569 and KF886570, respectively.

\subsection{Screening for OTA biodegradation}

The percentage of OTA that was eliminated by strains after a 7 day cultivation period in MRS-OTA is presented in Table 1. As mentioned previously, the biodegradation of OTA into OT $\alpha$ was only performed by $P$. parvulus strains that were isolated from Douro wines. In assays that involved the other bacterial strains, no OT $\alpha$ was detected even when some OTA was eliminated from the culture media (between $11 \%$ and $20 \%$, depending on the strain). Furthermore, when the chromatograms for the non-P. parvulus strains were compared to those of the controls (data not show), no other peaks that may have been the result of an alternative metabolisation pathway were detected. The slight elimination of OTA likely resulted from the inability of the extraction method to solubilise the OTA that was adsorbed onto the cell walls.

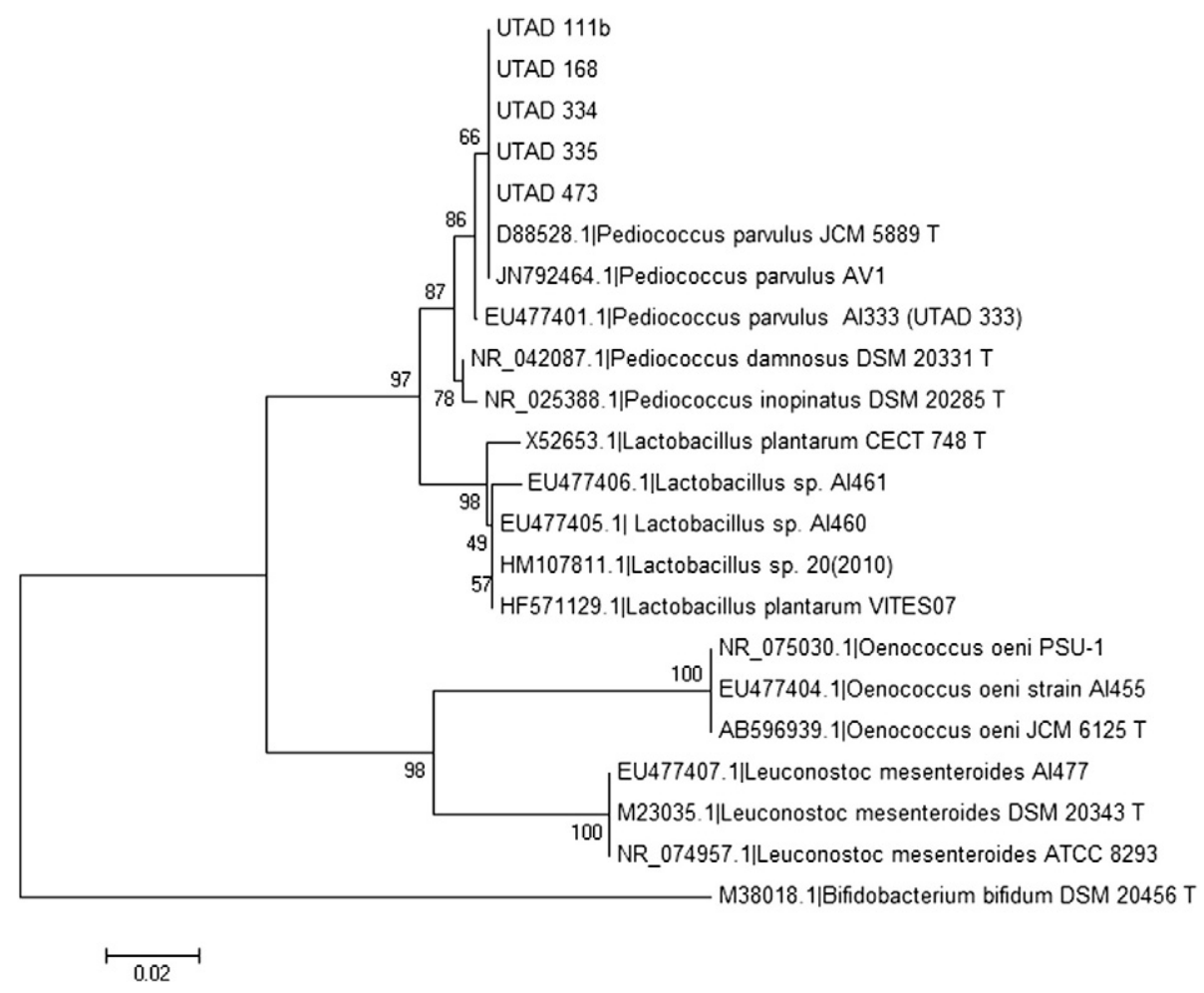

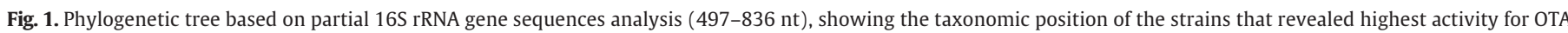
detoxification. 

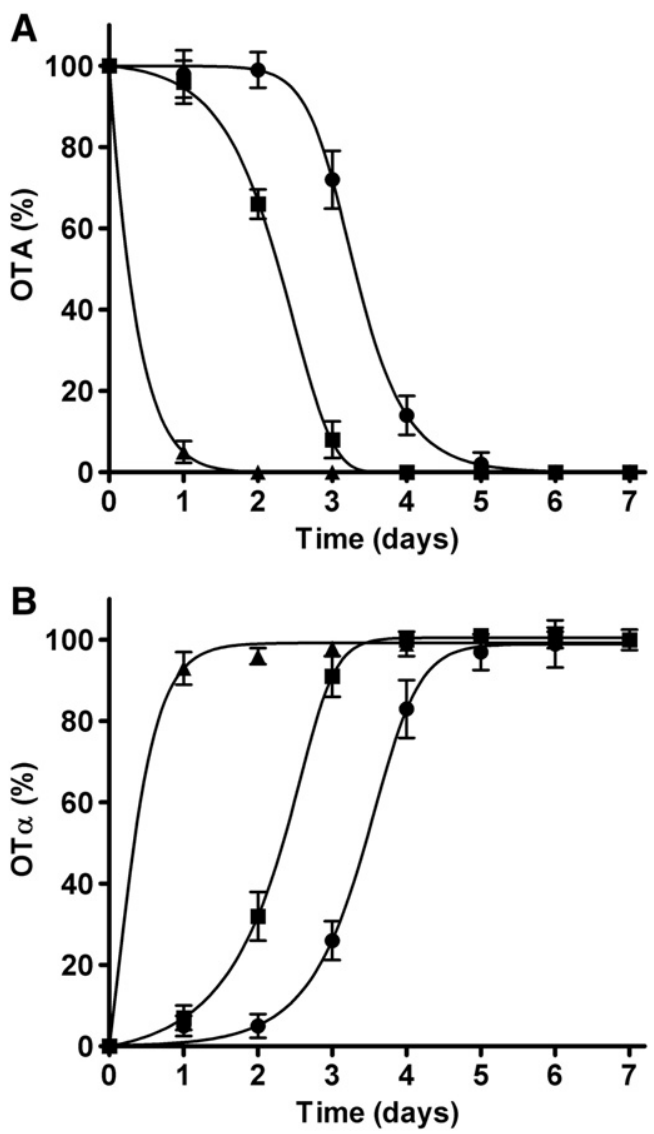

Fig. 2. Effect of the inoculum size on the biodegradation of OTA by P. parvulus UTAD 473 when cultivated in MRS-OTA medium. (A) OTA and (B) OT $\alpha$ concentration in the culture

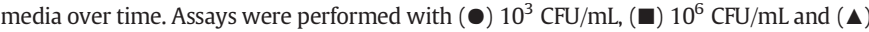
$10^{9} \mathrm{CFU} / \mathrm{mL}$. Data fitted using GraphPad Prism.

The highest biodegradation capacity was observed for the P. parvulus UTAD 473 strain. This strain completely eliminated OTA from the culture medium. Interestingly, the reference strain, $P$. parvulus CECT $7350^{\mathrm{T}}$, only eliminated $16 \%$ of the OTA from the culture medium and did not biodegrade OTA into OT $\alpha$. Therefore, the observed ability of P. parvulus to degrade OTA may be specific to the strains that were isolated from the Douro wines. Further investigation of the ability of $P$. parvulus UTAD 473 to biodegrade OTA was conducted by evaluating the effect of the concentration of the inoculum, the effect of OTA concentration in the culture media, and the effect of the incubation temperature. Additionally, the adsorption of OTA to the cell wall of the $P$. parvulus UTAD 473 strain was investigated.

Table 2

Effect of inoculum size, OTA concentration and temperature on the capacity of $P$. parvulus UTAD 473 to biodegrade OTA. The calculated values for DT50 and DT90 in hours are displayed.

\begin{tabular}{ccc}
\hline & DT50 $(\mathrm{h})$ & DT90 (h) \\
\hline Inoculum size & & \\
$10^{3} \mathrm{CFU} / \mathrm{mL}$ & 79 & 100 \\
$10^{6} \mathrm{CFU} / \mathrm{mL}$ & 55 & 70 \\
$10^{9} \mathrm{CFU} / \mathrm{mL}$ & 6 & 19 \\
OTA concentration & & \\
$0.01 \mu \mathrm{g} / \mathrm{mL}$ & 9 & 30 \\
$0.1 \mu \mathrm{g} / \mathrm{mL}$ & 6 & 25 \\
$1.0 \mu \mathrm{g} / \mathrm{mL}$ & 6 & 25 \\
Temperature & & 63 \\
$22{ }^{\circ} \mathrm{C}$ & 32 & 31 \\
$30{ }^{\circ} \mathrm{C}$ & 9 & 24 \\
$37{ }^{\circ} \mathrm{C}$ & 6 &
\end{tabular}

\subsection{Characterisation of OTA biodegradation by P. parvulus}

The effect of the inoculum size on the biodegradation of OTA is depicted in Fig. 2. It can clearly be observed that the conversion rate of OTA into OT $\alpha$ increased when the inoculum size was increased from $10^{3}$ to $10^{9} \mathrm{CFU} / \mathrm{mL}$. Additionally, a longer lag phase was observed in assays conducted with inoculums that were less concentrated. Therefore, a longer time was required to initiate the biodegradation of OTA and to achieve the total conversion of OTA into OT $\alpha$ in these cultures. Potentially, the cells required more time to adapt to the MRS-OTA medium and to synthesise the enzyme needed to degrade OTA. The effect of the inoculum size on OTA degradation was also observed when DT50 and DT90 were compared (Table 2). A decrease of $92 \%$ and $81 \%$, respectively, was observed for DT50 and DT90 when the inoculum size was increased from $10^{3}$ to $10^{9} \mathrm{CFU} / \mathrm{mL}$. When the most concentrated inoculum was used, the time required for $50 \%$ and 90\% OTA degradation was 6 and 19 h, respectively.

OTA biodegradation by $P$. parvulus UTAD 473 is also dependent on the incubation temperature (Table 2). Specifically, at $22{ }^{\circ} \mathrm{C}$ the DT50 and DT90 obtained were significantly longer compared to cultures at
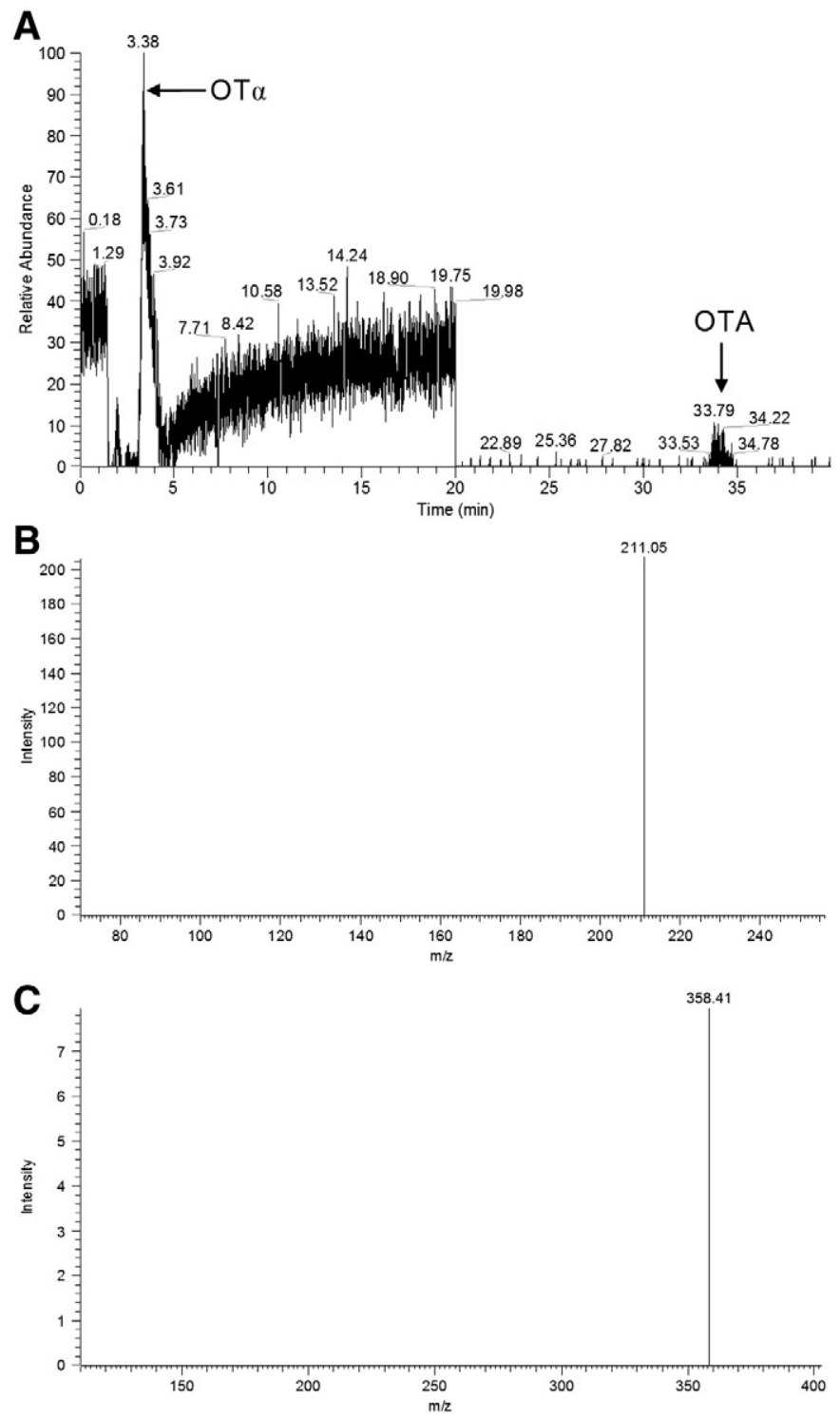

Fig. 3. Presence of OTA and OT $\alpha$ was confirmed by LC-MS/MS. (A) TIC chromatogram for P. parvulus UTAD 473 monitored from 0 to $20 \mathrm{~min}$ at $\mathrm{m} / \mathrm{z} 255$ and from 20 to $40 \mathrm{~min}$ at $\mathrm{m} / \mathrm{z}$ 402. (B) Mass spectrum after fragmentation of the OT $\alpha$ peak at 3.38 min in chromatogram A. (C) Mass spectrum of OTA peak at $34.00 \mathrm{~min}$ in chromatogram A. 
30 and $37{ }^{\circ} \mathrm{C}$. This indicated that OTA biodegradation rates decreased as a result of slower cell growth rates and slower enzymatic reaction rates. The difference in the DT50 and DT90 for the 30 and $37{ }^{\circ} \mathrm{C}$ cultures was small. However, a reduction in the DT50 and DT90 parameters was observed for the $37{ }^{\circ} \mathrm{C}$ culture compared to the $30{ }^{\circ} \mathrm{C}$ culture, which indicates a more rapid degradation of OTA at $37^{\circ} \mathrm{C}$. At $37{ }^{\circ} \mathrm{C}$ DT50 and DT90 were 6 and $24 \mathrm{~h}$, respectively.

In contrast to the previous factors, the concentration of OTA in culture media did not influence the biodegradation rate of the OTA. A slight increase in the DT50 and DT90 was observed for the $0.01 \mu \mathrm{g} / \mathrm{mL}$ OTA culture. This may suggest that OTA is required to induce the synthesis of the enzyme that is responsible for the biodegradation of OTA. The DT50 and DT90 that were identified for the 0.1 and $1.0 \mu \mathrm{g} / \mathrm{mL}$ OTA cultures were identical and were 6 and $25 \mathrm{~h}$, respectively, for each concentration of OTA.

For the assays that were conducted to evaluate the adsorption of OTA onto the P. parvulus cells, $98.7 \% \pm 1.6$ of the OTA remained in the culture media, and only $1.3 \% \pm 1.0$ of the OTA was adsorbed onto the bacterial cell walls. Therefore, the binding mechanism for the elimination of OTA is negligible.

\subsection{Ochratoxin $\alpha$ confirmation}

The LC-MS/MS analysis of the P. parvulus UTAD 473 sample indicated the presence of a peak with a retention time of 3.38 min that had the same mass transition characteristics $(\mathrm{m} / \mathrm{z} 255.0-211.0)$ of OT $\alpha$. A peak with a retention time of $34.00 \mathrm{~min}$ had the same mass transition characteristics ( $m / z 402.0-358.0)$ of OTA (Fig. 3). These data unequivocally identified OT $\alpha$ as the metabolite that resulted from OTA biodegradation by the P. parvulus strains that were isolated from the Douro wines.

\subsection{Evaluation of OTA biodegradation in food matrices by P. parvulus}

OTA biodegradation by $P$. parvulus UTAD 473 was observed in grape must but not in synthetic wine. The concentration of OTA and OT $\alpha$ detected over time in both matrices is shown in Fig. 4. In grape must, a 50\% and $80 \%$ reduction in the levels of OTA was observed after 3 and 6 days of incubation, respectively. In the wine cultures, no reduction in the levels of OTA was observed and no OT $\alpha$ was detected. Nonetheless, as it can be seen in Fig. 5, an increase of biomass (expressed by measuring OD at $600 \mathrm{~nm}$ ) was observed in both matrices, even if the bacteria grew better in must than in wine. The lack of elimination of OTA in synthetic wine may, eventually, be due to the presence of ethanol, which may have inhibited the enzyme responsible for the hydrolysis of OTA. The $\mathrm{pH}$ had no effect in this respect since it remained

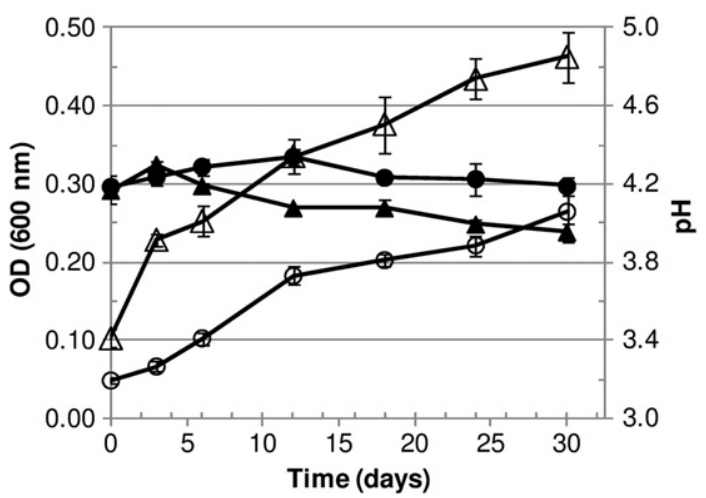

Fig. 5. Optical density (open symbols) and pH (closed symbols) over time of synthetic wine (circles) and grape must (triangles) supplemented with $7.0 \mu \mathrm{g}$ of OTA/L and inoculated with $P$. parvulus UTAD 473.

approximately the same in both matrices during the incubation period (Fig. 5).

\section{Discussion}

OTA is one of the most important mycotoxins that is found in food and feed products. Thus, research has been conducted to develop new and better strategies to reduce the negative impact of OTA to human and animal health. Several microorganisms that can biodegrade OTA into OT $\alpha$ have been identified (Abrunhosa et al., 2010; Varga et al., 2010). However, to the best of our knowledge, no reports clearly demonstrate the biodegradation of OTA by lactic acid bacteria. The existing studies either conclude that OTA was adsorbed onto the cell wall of LAB or did not allow the mechanism of elimination of OTA to be elucidated.

One of the first reports that studied the elimination of OTA from milk used the Streptococcus salivarius subsp. thermophilus, the Lactobacillus delbrueckii subsp. bulgaricus and Bifidobacterium bifidum (Skrinjar et al., 1996). OTA was observed to be completely eliminated at low levels $(0.05$ and $0.1 \mu \mathrm{g} / \mathrm{mL}$ ), but no biodegradation products were observed and no mechanisms for degradation were described. Similarly, Bohm et al. (2000) reported that several lactobacilli were effective at removing OTA from MRS media. L. bulgaricus 259/2 was observed to eliminate up to $94 \%$ of OTA. However, the authors did not determine whether the elimination of OTA was a result of biodegradation or adsorption. More recently, the elimination of OTA from culture media using oenological LAB species was also studied by Del Prete et al. (2007). In this study, the degradation of OTA was found to reach a
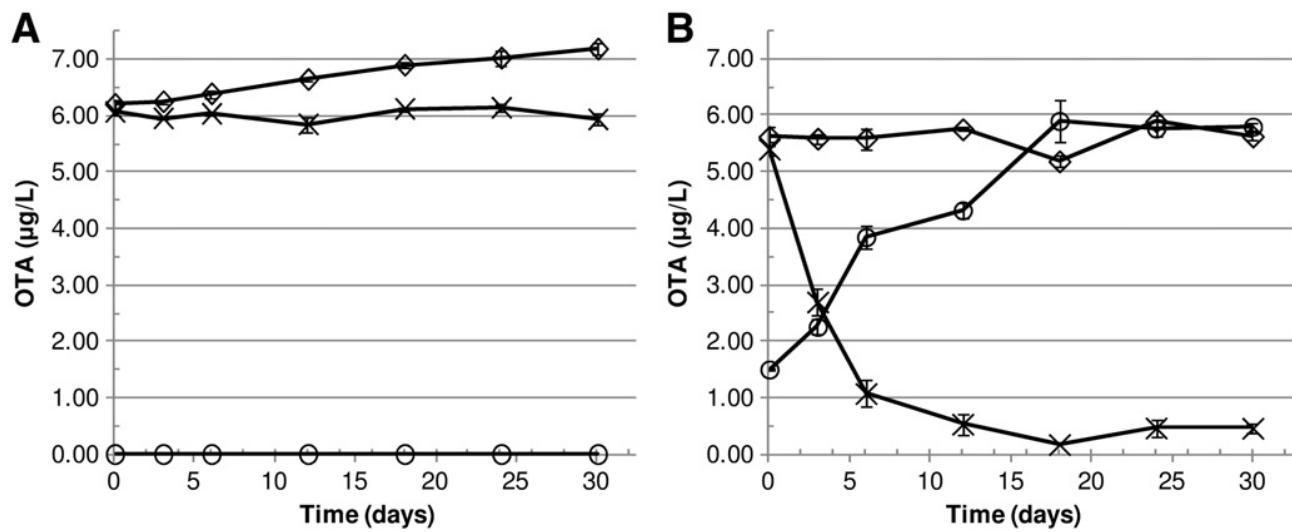

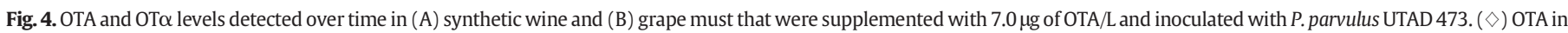
controls, $(\times)$ OTA in wine or grape must, and (O) OT $\alpha$ in wine or grape must. 
maximum of only $28 \%$, and no degradation products were detected. Thus, the authors concluded that a cell-binding phenomenon was most likely involved in the elimination of OTA. This finding is corroborated by our data because we obtained similar levels of elimination of OTA by the L. plantarum and O. oeni wine strains (elimination of up to $20 \%$ of the OTA in culture media) without having detectable OT $\alpha$ or other biodegradation products. Using a different approach, Fuchs et al. (2008) studied the capacity of LAB to eliminate OTA in buffer solutions. Lactobacillus acidophilus VM20 was identified to be the most active strain. This strain was able to remove greater than $95 \%$ of the OTA from the buffer solutions. In this study, the authors found that OTA was more efficiently removed by viable cells then by dead cells. Thus, the authors concluded that some metabolic degradation was involved, but they were not able to elucidate the mechanism of the elimination of OTA.

The present work is the first study that clearly describes the ability of LAB strains to biodegrade OTA. Specifically, $P$. parvulus strains were identified to be able to degrade OTA. This species is a Gram-positive and catalase negative LAB from the Lactobacillaceae family (Gunther et al., 1962). P. parvulus is a facultative anaerobe cocci that is strictly homofermentative and forms pares or tetrads. The bacteria can be associated with fermented vegetables, meat, fermented alcoholic beverages, dairy products and silage (Bennik et al., 1997; Holzapfel et al., 2006; Li et al., 2008; Maifreni et al., 2004; Mesas et al., 2011; Simpson et al., 2002; Tohno et al., 2012). P. parvulus also has some important probiotic properties: cholesterol-lowering effects as a result of exopolysaccharides that are produced (Martensson et al., 2005), immunomodulatory properties based on in vitro evidence, resistance to gastrointestinal stress and adherence to intestinal cells (de Palencia et al., 2009). Additionally, the bacteria have inhibitory effects on microorganisms as a result of produced pediocins (Immerstrand et al., 2010), and it has potential utility in the production of functional foods (GaraiIbabe et al., 2010). The use of $P$. parvulus has been successfully applied to sausage fermentation, and contributes to enhance the hygienic quality of sausage by inhibiting non-lactic acid bacteria (Li et al., 2008). This species has been described to have an important role in the fermentation of certain Belgian acidic beers (Martens et al., 1997) and has been shown to have some antifungal effects (Magnusson et al., 2003).

The pathway to biodegrade OTA that is used by the $P$. parvulus strains isolated from the Douro wines is the same pathway that has been identified in other microorganisms (Abrunhosa et al., 2010). Specifically, OTA is degraded via the hydrolysis of the OTA amide group and the subsequent release of the OT $\alpha$ and L- $\beta$-phenylalanine moieties. It is known that this hydrolysis is mediated at varying degrees of efficiency by some peptidases. The carboxypeptidase A enzyme from the bovine pancreas (Pitout, 1969), a commercial lipase (Stander et al., 2000), several commercial proteases and an OTA-hydrolytic enzyme isolated from Aspergillus niger (Abrunhosa et al., 2006), and carboxypeptidase Y from Saccharomyces cerevisiae (Abrunhosa et al., 2010), all can mediate the hydrolysis reaction. The hydrolysis of the amide bond of OTA is thought to mediate the detoxification of OTA because OT $\alpha$ is nontoxic.

In conclusion, because of the ability of the P. parvulus strains isolated from Douro wines to degrade OTA, one can appreciate their potential biotechnological application to reduce the health hazards associated with OTA. Because the strains mediate OTA biodegradation under anaerobic conditions, they may be suitable as silage inoculants or as feed additives. They may be of particular interest for swine nutrition because swine are the most susceptible livestock to the toxic effects of OTA. Typically, OTA levels that are detected in feed are significantly higher than the level found in food products. Therefore, applications for use in animal nutrition may be more valuable. Nevertheless, $P$. parvulus strains may have potential in human nutrition as observed in the assays performed in grape must. Some $P$. parvulus strains have already been found to be useful for sausage and beer fermentation, and others have shown properties that are relevant for probiotic applications. OTA-biodegrading P. parvulus may also be useful to eliminate OTA from wines. One potential strategy may involve the inoculation of wines with $P$. parvulus before alcoholic fermentation since it eliminates OTA in grape must. Inoculation of wines with malolactic bacteria and yeast at the same time has been advocated by some researchers because the bacteria have a better chance of growing and acclimatising to the media in the absence of ethanol and when nutrients are abundant (Bou et al., 2005). This strategy may be possible for the $P$. parvulus strains that degraded OTA. Even if some researchers associated $P$. parvulus with the ropiness of wine, others do not establish any direct association. For example, Fugelsang and Edwards (2007) consider in their book that it is possible that the growth of pediococci in wine may not adversely affect quality and may actually add desirable flavours and aromas under certain circumstances. Further studies should also be conducted to evaluate the contribution of these strains to the sensory characteristic and quality of wines.

\section{Acknowledgements}

This work was funded by FEDER funds through the "Programa Operacional Factores de Competitividade - COMPETE" and by national funds through "Fundação para a Ciência e a Tecnologia - FCT", Ref. FCOMP-01-0124-FEDER-028029 and PTDC/AGR-TEC/3900/2012, respectively. The authors also thank the FCT Strategic Project PEst-OE/ EQB/LA0023/2013 and the Project "Biolnd - Biotechnology and Bioengineering for improved Industrial and Agro-Food processes, REF. NORTE-07-0124-FEDER-000028" co-funded by the Programa Operacional Regional do Norte (ON.2 - O Novo Norte), QREN, FEDER. Luís Abrunhosa was supported by the grant SFRH/BPD/ 43922/2008 from FCT.

\section{References}

Abrunhosa, L., Venâncio, A., 2007. Isolation and purification of an enzyme hydrolyzing ochratoxin A from Aspergillus niger. Biotechnol. Lett. 29, 1909-1914.

Abrunhosa, L.,Santos, L.,Venâncio, A., 2006. Degradation of ochratoxin A by proteases and by a crude enzyme of Aspergillus niger. Food Biotechnol. 20, 231-242.

Abrunhosa, L.,Paterson, R.R.M.,Venâncio, A., 2010. Biodegradation of ochratoxin A for food and feed decontamination. Toxins 2, 1078-1099.

Bennett, J.W., Klich, M., 2003. Mycotoxins. Clin. Microbiol. Rev. 16, 497-516.

Bennik, M.H.J.,Smid, E.J., Gorris, L.G.M., 1997. Vegetable-associated Pediococcus parvulus produces pediocin PA-1. Appl. Environ. Microbiol. 63, 2074-2076.

Bohm, J., Grajewski, J., Asperger, H., Cecon, B., Rabus, B., Razzazi, E., 2000. Study on biodegradation of some A- and B-trichothecenes and ochratoxin A by use of probiotic microorganisms. Mycotoxin Res. 16 (Suppl. 1), 70-74.

Bou, M., Brown, N., Costello, P., Degré, R., Dieterich, W.,Gertsen-Briand, S., Kollar, S., Krieger, S., Kyne, A., Loubser, P., Morenzoni, R., Palacios, A., Powell, C., Specht, K., Specht, G., Theodore, D.,van Zandycke, S., 2005. Malolactic Fermentation in Wine - Understanding the Science and the Practice. Lallemand Inc., Montréal, Canada.

Dalié, D.K.D.,Deschamps, A.M.,Richard-Forget, F., 2010. Lactic acid bacteria - potential for control of mould growth and mycotoxins: a review. Food Control 21, 370-380.

de Palencia, P.F., Werning, M.L., Sierra-Filardi, E., Duenas, M.T., Irastorza, A., Corbi, A.L., Lopez, P., 2009. Probiotic properties of the 2-substituted (1,3)-beta-D-glucanproducing bacterium Pediococcus parvulus 2.6. Appl. Environ. Microbiol. 75, 4887-4891.

Del Prete, V., Rodriguez, H., Carrascosa, A.V., de las Rivas, B., Garcia-Moruno, E., Munoz, R., 2007. In vitro removal of ochratoxin A by wine lactic acid bacteria. J. Food Prot. 70, $2155-2160$

du Toit, M., Engelbrecht, L., Lerm, E., Krieger-Weber, S., 2010. Lactobacillus: the next generation of malolactic fermentation starter cultures - an overview. Food Bioprocess Technol. 4, 876-906.

EFSA, 2009. Scientific report submitted to EFSA (European Food Safety Authority). Review of Mycotoxin-detoxifying Agents Used as Feed Additives: Mode of Action, Efficacy and Feed/Food Safety (Available at: http://www.efsa.europa.eu/en/supporting/pub/ 22e.htm).

El-Nezami, H.,Kankaanpaa, P.,Salminen, S.,Ahokas, J., 1998. Ability of dairy strains of lactic acid bacteria to bind a common food carcinogen, aflatoxin B1. Food Chem. Toxicol. 36, 321-326.

El-Nezami, H., Mykkänen, H., Kankaanpää, P., Salminen, S., Ahokas, J., 2000. Ability of Lactobacillus and Propionibacterium strains to remove aflatoxin B1 from the chicken duodenum. J. Food Prot. 63, 549-552.

El-Nezami, H., Polychronaki, N., Salminen, S., Mykkanen, H., 2002a. Binding rather than metabolism may explain the interaction of two food-grade Lactobacillus strains with zearalenone and its derivative $\alpha$-zearalenol. Appl. Environ. Microbiol. 68, 3545-3549. 
El-Nezami, H.S., Chrevatidis, A., Auriola, S., Salminen, S., Mykkanen, H., 2002b. Removal of common Fusarium toxins in vitro by strains of Lactobacillus and Propionibacterium. Food Addit. Contam. 19, 680-686.

El-Nezami, H., Salminen, S., Salminen, E., Haskard, C., Mykkanen, H., 2004. Lactic acid bacteria as a tool for enhancing food safety by removal of dietary toxins. In: Seppo, S., von Wright, A., Ouwehand, A. (Eds.), Lactic Acid Bacteria. Marcel Dekker, Inc., New York, pp. 397-406.

Felsenstein, J., 1985. Confidence-limits on phylogenies - an approach using the bootstrap. Evolution 39, 783-791.

FOCUS, 2006. Guidance document on estimating persistence and degradation kinetics from environmental fate studies on pesticides in EU registration. Report of the FOCUS Work Group on Degradation Kinetics, EC Document Reference Sanco/10058 2005 Version 2.0 (434 pp. Available at: http://focus.jrc.ec.europa.eu/dk/docs/ finalreportFOCDegKin04June06linked.pdf.).

Fuchs, S., Sontag, G., Stidl, R., Ehrlich, V., Kundi, M., Knasmuller, S., 2008. Detoxification of patulin and ochratoxin A, two abundant mycotoxins, by lactic acid bacteria. Food Chem. Toxicol. 46, 1398-1407.

Fugelsang, K.C., Edwards, C.G., 2007. Wine microbiology, Practical Applications and Procedures2nd ed. Springer, New York, USA.

Garai-Ibabe, G., Duenas, M.T., Irastorza, A., Sierra-Filardi, E., Werning, M.L., Lopez, P., Corbi, A.L., Fernandez de Palencia, P., 2010. Naturally occurring 2-substituted (1,3)-beta-D-glucan producing Lactobacillus suebicus and Pediococcus parvulus strains with potential utility in the production of functional foods. Bioresour. Technol. 101, 9254-9263.

Gunther, H.L., Coster, E., White, H.R., 1962. Designation of the type strain of Pediococcus parvulus Gunther and White. Int. Bull. Bacteriol. Nomenclature Taxon. 12, 189-190.

Holzapfel, W.H., Franz, C.M.A.P., Ludwig, W., Back, W., Dicks, L.M.T., 2006. The genera Pediococcus and Tetragenococcus, In: Dworkin, M., Falkow, S., Rosenberg, E., Schleifer, K.H., Stackebrandt, E. (Eds.), The Prokaryotes. Bacteria: Firmicutes, Cyanobacteria, Part 1 ed.Springer, US, pp. 229-266.

Immerstrand, T., Paul, C.J., Rosenquist, A., Deraz, S., Martensson, O.B., Ljungh, A., Blucher, A. Oste, R., Holst, O., Karlsson, E.N., 2010. Characterization of the properties of Pediococcus parvulus for probiotic or protective culture use. J. Food Prot. 73, 960-966.

Inês, A.F.H., 2007. Polyphasic Approach to the Characterization and Selection of Lactic Acid Bacteria of Wines From the Douro Region. Universidade de Trás-Os-Montes e Alto Douro, Vila Real, pp. 1-198 (Available at: http://repositorio.utad.pt/bitstream/ 10348/101/1/phd_aines2007.pdf).

Inês, A.,Tenreiro, T.,Tenreiro, R.,Mendes-Faia, A., 2008. Screening enzymes with enological relevance in lactic acid bacteria isolated from Douro wines. Am. J. Enol. Vitic. 59, $330 \mathrm{~A}-351 \mathrm{~A}$.

Jørgensen, K., 2005. Occurrence of ochratoxin A in commodities and processed food: a review of EU occurrence data. Food Addit. Contam. 22, 26-30.

Kimura, M., 1980. A simple method for estimating evolutionary rates of base substitutions through comparative studies of nucleotide sequences. J. Mol. Evol. 16, 111-120.

Kunkee, R.E., 1967. Malo-lactic fermentation. In: Wayne, W.U. (Ed.), Advances in Applied Microbiology. Academic Press Inc., London, pp. 235-279.

Lerm, E., 2010. The Selection and Characterisation of Lactic Acid Bacteria to be Used as a Mixed Starter Culture for Malolactic Fermentation. Department of Viticulture and Oenology, Faculty of AgriSciences, Stellenbosch University, South Africa, p. 151.

Li, S., Marquardt, R.R., Frohlich, A.A., Vitti, T.G., Crow, G., 1997. Pharmacokinetics of ochratoxin A and its metabolites in rats. Toxicol. Appl. Pharmacol. 145, 82-90.

Li, P.L., Shen, Q.W., Liu, Z.Y., Fu, P., Zhou, W., 2008. A newly isolated strain Pediococcus parvulus from Xuanwei ham, a traditional Chinese fermented meat product. Int. J. Food Sci. Technol. 43, 1387-1394.

Magnusson, J., Strom, K., Roos, S., Sjogren, J., Schnurer, J., 2003. Broad and complex antifungal activity among environmental isolates of lactic acid bacteria. FEMS Microbiol. Lett. 219, 129-135.

Maifreni, M., Marino, M., Conte, L., 2004. Lactic acid fermentation of Brassica rapa: chemical and microbial evaluation of a typical Italian product (brovada). Eur. Food Res. Technol. 218, 469-473.
Martens, H., Iserentant, D., Verachtert, H., 1997. Microbiological aspects of a mixed yeastbacterial fermentation in the production of a special Belgian acidic ale. J. Inst. Brew. $103,85-91$

Martensson, O., Biörklund, M., Lambo, A.M., Dueñas-Chasco, M., Irastorza, A., Holst, O. Norin, E., Welling, G., Öste, R.,Önning, G., 2005. Fermented, ropy, oat-based products reduce cholesterol levels and stimulate the bifidobacteria flora in humans. Nutr. Res. 25, 429-442.

Mateo, E.M., Medina, A., Mateo, R., Jimenez, M., 2010. Effect of ethanol on the ability of Oenococcus oeni to remove ochratoxin A in synthetic wine-like media. Food Control 21, 935-941.

Mesas, J.M., Rodriguez, M.C.,Alegre, M.T., 2011. Characterization of lactic acid bacteria from musts and wines of three consecutive vintages of Ribeira Sacra. Lett. Appl. Microbiol. 52, 258-268.

Naidu, A.S., Bidlack, W.R., Clemens, R.A., 1999. Probiotic spectra of lactic acid bacteria (LAB). Crit. Rev. Food Sci. Nutr. 39, 13-126.

Niderkorn, V., Morgavi, D.P., Pujos, E., Tissandier, A., Boudra, H., 2007. Screening of fermentative bacteria for their ability to bind and biotransform deoxynivalenol, zearalenone and fumonisins in an in vitro simulated corn silage model. Food Addit. Contam. 24, 406-415.

Pitout, M.J., 1969. The hydrolysis of ochratoxin A by some proteolytic enzymes. Biochem. Pharmacol. 18, 485-491.

Ruhland, M., Engelhardt, G., Wallnofer, P.R., 1996. Transformation of the mycotoxin ochratoxin A in plants. 2. Time course and rates of degradation and metabolite production in cell-suspension cultures of different crop plants. Mycopathologia 134, 97-102.

Saitou, N., Nei, M., 1987. The neighbor-joining method: a new method for reconstructing phylogenetic trees. Mol. Biol. Evol. 4, 406-425.

Salminen, S., Nybom, S., Meriluoto, J., Collado, M.C., Vesterlund, S., El-Nezami, H., 2010 Interaction of probiotics and pathogens-benefits to human health? Curr. Opin. Biotechnol. 21, 157-167.

Shetty, P.H., Jespersen, L., 2006. Saccharomyces cerevisiae and lactic acid bacteria as potential mycotoxin decontaminating agents. Trends Food Sci. Technol. 17, 48-55.

Simpson, P.J., Stanton, C., Fitzgerald, G.F., Ross, R.P., 2002. Genomic diversity within the genus Pediococcus as revealed by randomly amplified polymorphic DNA PCR and pulsed-field gel electrophoresis. Appl. Environ. Microbiol. 68 765-771.

Skrinjar, M., Rasic, J.L.,Stojicic, V., 1996. Lowering of ochratoxin A level in milk by yoghurt bacteria and bifidobacteria. Folia Microbiol. 41, 26-28.

Stander, M.A., Bornscheuer, U.T., Henke, E., Steyn, P.S., 2000. Screening of commercial hydrolases for the degradation of ochratoxin A. J. Agric. Food Chem. 48, 5736-5739.

Stiles, M.E., 1996. Biopreservation by lactic acid bacteria. Antonie Van Leeuwenhoek 70 $331-345$.

Tamura, K., Peterson, D., Peterson, N., Stecher, G., Nei, M., Kumar, S., 2011. MEGA5: molecular evolutionary genetics analysis using maximum likelihood, evolutionary distance, and maximum parsimony methods. Mol. Biol. Evol. 28, 2731-2739.

Tohno, M., Kobayashi, H., Nomura, M., Kitahara, M., Ohkuma, M., Uegaki, R., Cai, Y., 2012 Genotypic and phenotypic characterization of lactic acid bacteria isolated from Italian ryegrass silage. Anim. Sci. J. 83, 111-120.

van der Merwe, K.J., Steyn, P.S., Fourie, L., 1965. Mycotoxins. Part II. The constitution of ochratoxins A, B, and C, metabolites of Aspergillus ochraceus Wilh. J. Chem. Soc. 7083-7088.

Varga, J., Kocsube, S., Peteri, Z., Vagvolgyi, C., Toth, B., 2010. Chemical, physical and biological approaches to prevent ochratoxin induced toxicoses in humans and animals. Toxins 2, 1718-1750.

Wu, Q., Dohnal, V., Huang, L., Kuca, K., Wang, X., Chen, G., Yuan, Z., 2011. Metabolic pathways of ochratoxin A. Curr. Drug Metab. 12, 1-10. 